\title{
Activity theory as a potential framework for technology research in an unequal terrain
}

\section{J. Hardman}

\author{
University of Cape Town, Rondebosch, South Africa \\ e mail: jhardman@humanities.uct.ac.za
}

\begin{abstract}
This article attempts to expand and elaborate Activity Theory as a theory for studying human computer interaction in South Africa. It first sketches ways in which Russian activity theory arising out of the work of Vygotsky may expand understandings of learning before elaborating the theory in terms of Engestrom's contributions. Using case study data collected from a postgraduate course in Education at the University of Cape Town, I investigate how Activity Theory can be used in order to understand the process of transformation occurring when computers are used as teaching/learning tools and how different systems interact with, and transform each other over time. By employing methods such as interviews and observations I develop an account of how pedagogy shifts across the different contexts of lecture hall and computer laboratory, illustrating how a shift in the object of the activity system leads to shifts at all levels of the system. I conclude by arguing that the strength of Activity Theory lies in its ability to enable one to understand learning as the complex result of tool mediated interactions, rather than as something opaque, which happens in a student's mind.
\end{abstract}

\section{INTRODUCTION}

Post Apartheid South Africa continues to face the challenge of ensuring access to higher education for all. The challenge arises due to the need to meet the diverse learning needs of a heterogeneous student body, which is prepared to a greater or lesser degree to engage with academia. Anecdotal evidence from prior courses where academic underachievement posed a problem for many students, indicated that some students' enrolled for the postgraduate course in 'Learning and Cognition' struggled to engage with academic tasks due in part to their inability to interpret (and indeed to pose) the kinds of questions they faced in these tasks. Clearly, if students are unable to ask the kinds of critical open-ended questions that are typical of the human sciences, they will struggle to engage with these questions. There is then, a clear disjuncture between what students bring to academic tasks and what the task demands. The challenge facing the author, then, was the development of 'tools' capable of bridging this gap by mediating students' engagement with critical questioning skills (Hardman and Ngambi 2003; Ngambi and Hardman 2004). There is currently mounting evidence that appropriately designed computer software coupled with suitable pedagogical strategies can develop students' higher order thinking skills (Fontana et al. 1993; Jonassen and 
Carr 2000; Kearney and Treagust 2001; Lim and Chai 2004). Consequently, I turned to the computer as a potential environment in which to build tools (in the form of online environments) that could essentially 'mediate' students' engagement with critical questioning skills. Having not used computers extensively for teaching/learning before, I became increasingly interested in the potential impact of this tool on my pedagogical practice. Consequently, the main question driving this article is an investigation into how a lecturer uses a computer-based questioning environment to mediate critical questioning skills. Reconstituted in the language of activity theory, this question seeks then to understand whether:

- The introduction of a computer-based environment forces a change in the activity systems of the classroom, challenging stabilised (operationalised) ways of acting on the object of each system and, consequently, (hypothetically) requiring new ways of acting.

\section{PSYCHOLOGICAL TOOLS AND MEDIATED LEARNING: MIND IN SOCIETY}

Ten years after the first democratic elections, South Africa continues to face educational challenges as it attempts to break from the previous acquisition model of learning to a view of learning as actively negotiated. Transmission models of learning, where skilled teachers view children as empty vessels easily filled, have long predominated in psychological and educational circles (Sfard 1998). However, studies indicating that students are much more actively involved in learning than transmission models allow for have seriously challenged this model of learning (Kozulin 2003). In their search for alternative models to explain learning, many researchers have turned their attention to Vygotsky's notion of mediation, where a more competent peer or adult is viewed as assisting performance, bridging the gap between what the child knows and can do and what the child needs to know. Vygotsky (1978) conceptualised this gap between unassisted and assisted performance as the zone of proximal development (ZPD) that 'space' where learning leads to development. Crucially, for Vygotsky (1978) (and indeed for all activity theorists who have followed in his footsteps) human consciousness is social (Nardi 1998). What we have here, then, is a theory that overcomes the Cartesian dualism that currently permeates various powerful paradigms in human computer interaction research such as cognitive science, which continues to locate cognitive functioning within the rational individual. Essentially, Vygotsky enables us to conceptualise the prior existence of complex cognitive structures as existing in the child's culture, rather than in the individual child. That is, for Vygotsky the child never approaches the world 'clean'; rather, every experience the child has is mediated through cultural tools. Figure 1 illustrates the basic Vygotskian triangular representation of mediation, where the subject acts on the object using mediational means (tools).

For Vygotsky (1978) humans use tools to change the world and are themselves transformed through tool use. While this representation opens the way towards an 
Mediational means (Tools)

(machines, writing, speaking, gesture, architecture, music, etc.)

Subject(s)

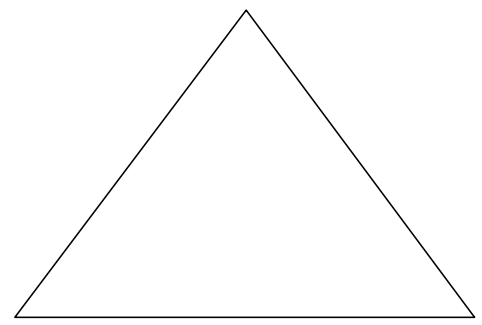

(Individual, dyad, group)

$$
\text { Object/Motive } \rightarrow \text { Outcome(s) }
$$

Figure 1: Basic Vygotskian triangular representation of mediation

understanding of learning as transformation rather than transmission, it lacks an articulation of the individual subject and his/her role in the societal structure. Activity theory as developed by Engestrom $(1987 ; 1996)$ takes the object-oriented, tool mediated collective activity system as its unit of analysis, thereby bridging the divide between the subject and the societal structure (Daniels 2001). It is this activity theory tradition that has been taken up enthusiastically by those working with human computer interaction (Bodker 1989, 1991; Kaptelinin 1996; Kuutti 1996; Nardi 1996; Zinchenko 1996; Russell 2002). If we think of computers as cultural tools, then we need to be able to ask and answer questions related to how these tools facilitate learning and, relatedly, how teachers and students change the computer and are transformed by it over time. Activity theory can be used in order to understand this process of transformation within a system (such as a classroom/ university laboratory) as well as illustrating how different systems interact with, and transform each other over time (Engestrom 1987). The strength of activity theory is that it enables one to understand learning as the complex result of tool mediated interactions, rather than as something opaque which happens in a student's mind.

\section{BASIC PRINCIPLES}

While activity theory is best understood as a developing body of knowledge, there are some basic principles that are shared by those working within the field. I draw primarily from Cole (1996) and Russell (2002) in order to elaborate these principles:

- Human activity is collective and human behaviour originates within the social realm (Cole and Engestrom 1993). Even an apparently solitary task such as sitting in front of the computer typing this article is a collective activity. My actions are mediated by a complex network of socio-historically embedded tools, such as the papers I am referring to while writing this. 
- Mind is social, growing out of joint activity.

- Tools, which carry socio-historical meanings, mediate our psychology.

- Activity theory studies development and change, which is understood to include historical change, individual development and moment-to-moment change (Russell 2002). When studying computer mediated learning it is important to focus on all three levels of change in order to construct a picture of human computer interaction.

- Activity theory assumes that people are active cognising agents but that they act in sites that are not necessarily of their choosing with tools that constrain and afford their actions.

- Methodologically, activity theory rejects cause and effect explanatory science in favour of 'a science that emphasises the emergent nature of mind in activity and acknowledges a central role for interpretation in its explanatory framework' (Cole 1996, 104). Consequently, activity theorists make use of a contextualist methodology.

- Activity systems are constantly subject to change and activity theory sees these changes as driven by contradictions (Engestrom 1987; Russell 2002). Contradictions, or double binds, can arise within and between systems.

\section{AN ACTIVITY SYSTEM}

For activity theory the basic unit of analysis is an activity system. Briefly, this refers to a group of people, or a community, who share a common object (or problem space) and who use tools to act on that object, transforming it. The object is represented as a circle indicating that this space is subject to change and is in a state of flux, making it difficult to pin down. Relationships in this system are driven by rules, which both afford and constrain behaviour. Division of labour within the system describes both a horizontal division among community members, as well as a vertical division between power- and status-holders. Figure 2 elaborates the basic relationships in an activity system.

Very briefly, the assumption underlying the analysis reported in this article is that the introduction of computers to mediate critical questioning skills has (potentially) 'forced' a change in the activity systems of lecture hall, challenging stabilised (operationalised) ways of acting on the object of each system and, consequently, requiring new ways of acting. Taking the computer based 'Learning and Cognition' lesson as an activity system, the lecturer (subject) acts on the students' understanding (object) in order to transform it using a computer-based questioning environment (mediating artefact) in order to arrive at critical questioning skills (outcome). In turn, the lecturer's pedagogic position is influenced by the rules of the computer laboratory, which can be the general rules and regulations of the university or more specific rules such as those procedures required to use the online environment. The community in this lesson includes the students, the software designer, a technician and the lecturer who are 


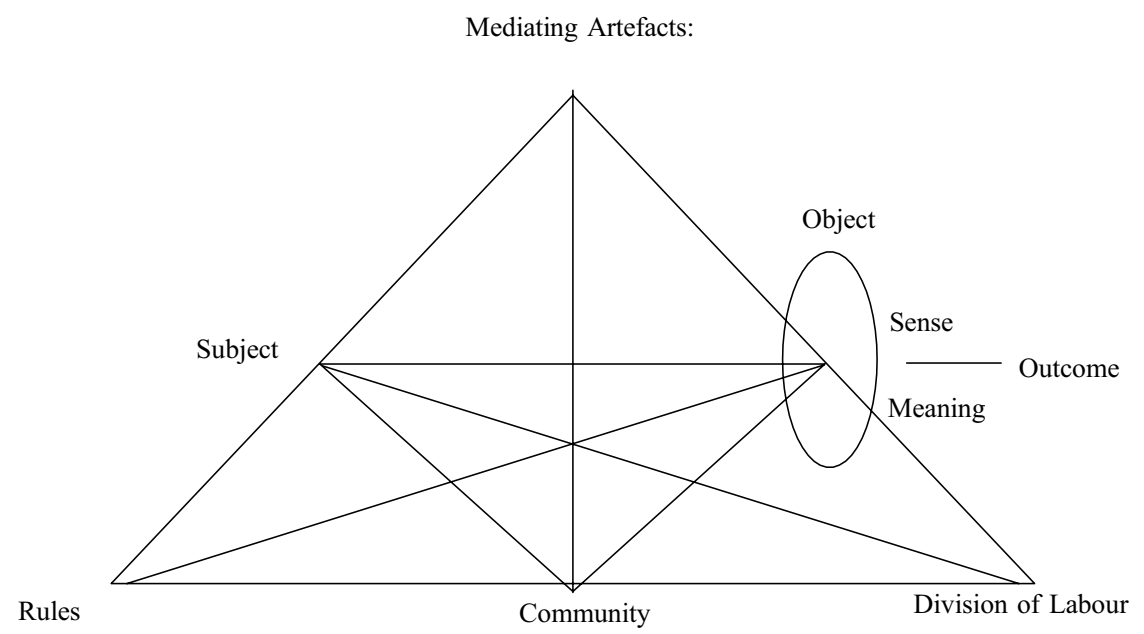

Figure 2: Activity system

all working together on the primary object, students' questioning skills. However, while sharing an object, we have different roles to play in acting on it. These different roles fall under division of labour, with the students generally expected to engage with the environment and the lecturer expected to guide that interaction.

\section{THE ONLINE ENVIRONMENT}

While this article does not deal with the technical design of the environment (interested readers are referred to Hardman and Ngambi 2003; Ngambi and Hardman 2004; Ngambi 2002a) a brief description of the environment serves to situate the study in a particular context. A web-based environment capable of capturing students' questions and student and lecturer responses was designed. This Dynamic Frequently Asked Questions (DFAQ) environment stores users' questions in a database before emailing each question to the lecturer. The lecturer answers the questions in the online environment. Students have access to all questions and responses in the environment. Students were required to interrogate two core texts placed in this online environment. These texts were chosen for this environment because they are sufficiently complex to provoke questioning and because they contain theoretical concepts that are essential to this course. The texts were electronically available and could be opened in a separate window. Figure 3 shows the interface used to ask questions. Interaction in the environment is anonymous for the students. The lecturer, however, is able to track interaction as students are required to log into the environment using their student login. 


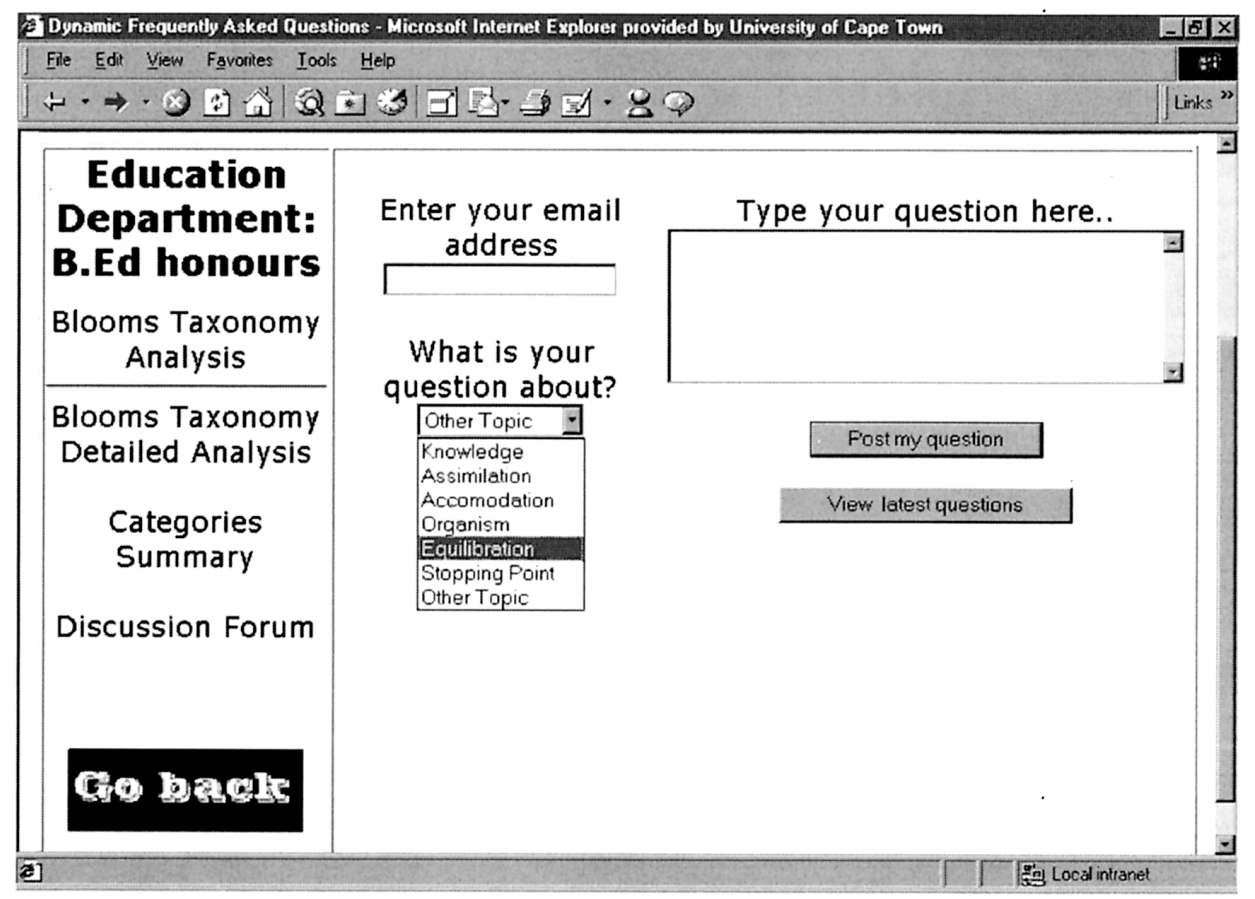

Figure 3: User interface

All questions asked were recorded in a database. Students are able to view all the questions posted as well as responses to these questions. The thinking behind the environment is that it provides a dynamic database of questions enabling students to

1. practise questioning skills,

2. receive answers to their questions and

3. provide space for the lecturer to model appropriate questioning skills for students.

Perhaps one of the most useful aspects of the environment, for the lecturer at least, is the fact that student and lecturer questions remain available for discussion outside of the lecture period, allowing one to return to questions and responses when one has had time to reflect on the lesson.

\section{RESEARCH DESIGN AND METHODS}

As this study seeks to uncover the process of mediation within a computer laboratory it is important that the design is able to provide deep descriptions of this process. This focus on a process type question coupled with a limited sample led me to select a case study as my preferred design. The case reported in this study is 
a postgraduate Bachelor of Education (B.Ed.) course at the University of Cape Town (UCT) entitled 'Learning and Cognition', which ran for a semester from February 2002 until June 2002. All 20 students registered for the B.Ed honours course 'Cognition and Learning' and the lecturer participated in this research. All these students are in service teachers. 80 per cent $(n=16)$ of the participants are female and 85 per cent $(n=17)$ of the participants could be described as coming from previously disadvantaged communities. Participants' average age is 35 years, with the youngest participant 24 years of age and the oldest 45 years of age. Although this is a very small group, the subject profile generated for this group suggests that it is reflective of the overall profile of the 90 students registered for a B.Ed. Honours degree at the University of Cape Town. Before proceeding, I feel it is important to discuss the dual role I hold in this project, as both lecturer (the subject in this case) and researcher. I am the first to acknowledge that this position is not a comfortable one, especially in light of threats to validity that emerge due to bias that must surely arise from this awkward situation. Acknowledging this potential bias is the first step towards dealing with it; a further cautionary step has involved using a research assistant to video tape the lectures, conduct the interviews and to assist in analysing the data. Further, as this research was carried out nearly two years ago, time has given me some distance from the data.

\section{Procedure}

As the focus of this study is on pedagogical shifts hypothesised to occur through the introduction of computer based learning, computer based lectures and face-toface lectures were video taped. As the lecturer's pedagogy is consistent across lectures, only two $1 \frac{1}{2}$ hour lectures and two computer lessons were selected for indepth study. The comparison, then, is between face-to-face and computer-based teaching. The focus of the analysis for this article is on the potential impact a computer-based learning environment has on pedagogical practices and not on an evaluation of the particular environment. In order to triangulate findings students were given questionnaires to fill in regarding their experience of the computer and face-to-face lectures and three students were chosen to be interviewed. These students were selected from high, middle and low achievers (as determined by the final grade they obtained for the course) and were interviewed by my research assistant. My research journal for this period served as a further source of data, to elucidate my personal experiences.

\section{Data analysis}

Six hours of video data (two face-to-face and two computer lessons) were transcribed. The transcribed text was analysed in terms of categories drawn from activity theory, namely: subject position; tools; object; rules, community and division of labour. 


\section{FINDINGS AND DISCUSSION}

The activity system of the face-to-face lecture

In order to ascertain whether the introduction of a computer-based learning environment forces a shift in pedagogical practice, it is necessary to first elaborate the structure of a face-to-face lecture where no computers are used. Figure 4, below, is a graphic representation of data gathered from interviews with three students, video data and my research journal.

Tools: Language (teacher): whole class instruction; OHP; course notes written by lecturer

Subject: Lecturer Students learn through active engagement

Rules: UCT's policies around access and equity; more specific rules about doing assignments on time; class attendance etcetera

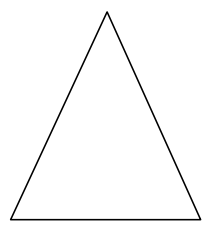

Object Content; conceptual understanding (scientific concepts)

\section{Outcome} understanding
Community: students
Division of Labour lecturer as didact; lecturer determines pace and sequence

Figure 4: In the face-to-face lesson

Object: The object of an activity system is that problem space that the subject acts on and transforms. My object during lectures is both to cover the content of the course and to develop students' understanding of the course, while developing their critical engagement skills. I attempt to do this by linking students' everyday knowledge to the more abstract concepts I intend to develop. This movement from the concrete to the abstract is captured in student 2's interview response in extract 1 below. What we see in extract 1 is how the lecturer tries to link concrete, everyday experiences with the more abstract formalised language of Piaget's theory. Reconstituted in the language of activity theory, the object of this activity then, is scientific concepts.

\section{Extract 1: The object of the lesson}

RA: Was this a typical lecture? Could you explain to me what you were working on in the lesson that we just observed?

Student 2: Ja, I think it's typical. Today we are working with Piaget and he's talking about um, development, cognitive development. So today we are talking about the preoperational stage and um, we, we talked about our own children and I gave this example of my child, she's 5, and we had her 
birthday and oh, but there was trouble when we came to pour juice, because we didn't have um, all mug, all mugs weren't the same size. So you can just imagine! There are these children not happy if they have a big mug because the juice looks too little. So Joanne (the lecturer) said, $\mathrm{Ok}$, this is an example of a child who is not able to conserve. Um, so that is the Piagetian word 'conserve', so now I thought, oh, ok, so that is what it is about! (Smiles)

Rules: My focus on transforming scientific concepts is influenced by current social rules and regulations that both support and constrain activity. In this instance, the current policy shift from traditional pedagogy to outcomes based pedagogy and the consequent shift from a focus on passive to active students coupled with UCT's commitment to equity and access impacts on the types of tools I select to act on students' scientific concepts. At the micro level, there are rules, such as rules around assessments that govern interaction within the lecture hall, as indicated by student 1 in extract 2 .

Extract 2: Rules in the lecture hall

RA: Can you identify rules that everyone follows in the lecture hall?

Student 1: Rules? Like?

RA: I think I am looking for accepted practices, you know, who does what. Rules that determine that?

Student 1: Ok, like, uh, for example when the lecturer talks no one else talks?

RA: Yes, like that.

Student 1: Well, that's an unspoken rule. Other rules are ok; don't interrupt someone when they're talking. Oh yes, and rules about assessments and course attendance. We have a DP requirement, $80 \%$ attendance or you can't write the exam. Uh, things like that.

Subject position and tools: A teacher's epistemic assumptions or subject position, impact on the type of tools they use to teach, which in turn influences how they act on the object of the activity. As someone who is firmly embedded in sociocultural activity theory, I take very seriously the notion that tools mediate our intellectual growth. Like Vygotksy $(1978 ; 1962)$ I view language as possibly the most important psychological tool and, consequently, I tend to rely heavily on discursive tools in my teaching.

Community: While the community of the lecture hall includes me and my students, we are members of wider communities whose influences we bring to bear on the object.

Division of labour: I am primarily responsible for determining the pace and selecting the sequence of work covered in the classroom. As the students 
sometimes work in groups, there is both horizontal division of labour between them, with students sharing knowledge and skills and vertical division of labour between them, with brighter students often dominating the group.

This article focuses particularly on whether the introduction of a new tool, in this instance the computer, impacts on how a lecturer mediates content in a postgraduate course. Consequently, the comparison in this analysis is between a lecturer's face-to-face lessons and computer laboratory lessons. Figure 5 below is a graphic representation of interview and observational data relating to the use of computers within my lesson.

Tools: Computer online DFAQ environment; Language

Subject: Lecturer

Knowledge of computer usage is essential for in service teachers; computers have the potential to act as cognitive tools

Rules: 'Informationisation' of society requires that students are computer literate; ICT policy at UCT; ICT policy in SA these are teachers, they need to be computer literate

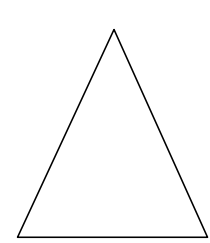

Community: students; technician; designer
Object 'Personality' Technical skills; computer; motivation

Outcome: technologically literate teachers; critical questioning skills

Division of Labour shift in roles

Figure 5: In the computer laboratory

Object: It is extremely difficult to pin down the object of an activity system, as the object shifts dynamically while it is being acted on. However, it is possible to discern objects in both the video data and the interview data. Extract 3 and 4 highlight some of the objects in the computer lesson. What we can see is that the object of the lesson initially became computer use itself, rather than the development of critical questioning skills. Something I had not anticipated was the computer's ability to impact on the personal development of students. In extracts 4 and 5 we see that the computer has had a positive effect on this student's confidence, which has spilled over into her home and working life. I have called this object 'personality'. I refer to 'personality' in inverted commas as I wish to draw a distinction between western psychology's view of personality as inherently belonging to the person and 'not causally related to the social context' and Soviet psychology's understanding of 'lichnost', which can be loosely translated as personality, but which views it as socially constructed (Valsiner 1998; Daniels 
2001). A further object emerging from the data is motivation. In this instance, the computer is being used to act on students' motivation. As motivation is necessary for learning, one could reasonably infer that the computer's ability to motivate students will ultimately impact on their academic success.

\section{Extract 3: The object in the computer laboratory}

RA: Could you explain to me what you were working on in the lesson that we just observed?

Student 1: Ok, uh, we were working on this online environment, that, uh, that Dick has designed. So what we had to do was to uh ask questions, read the paragraphs that were there and then ask questions. And we could answer questions too.... Ok, but uh, you also have to understand that only three people in the class had used computers before, so quite a lot of time was spent you know, doing technical stuff. I mean, ok, some of the people didn't even know how to log in or what a mouse was. No, I'm not joking, hey! This one woman Josey she couldn't use the mouse at all, I mean at all. So we spent time doing basic things like using the mouse, basic technical things like that.

\section{Extract 4: Motivation and confidence}

RA: Could you explain to me what you were working on in the lesson that we just observed?

Student 3: Yes we have to use the computer to ask questions and get some answers. ... I have never used a computer before, never! And now, shew, I can just get into it, just how they say, log in. It's terrific, terrific, makes you want to come to every lecture! (Laughs) I can't tell you how important is this computer, for me. I can go, go to school and I can go to the office and use the computer, surf the web, jy weet (you know) and all those things. I feel much more confident, much more. I can even show my grandkids, look ouma knows this thing!

\section{Extract 5: 'Personality'}

RA: Can you describe the impact the computer has had on your work?

Student 2: I can say a big impact. Especially in school. I could never use this computer before, I just didn't know how is it you use this. And I have an 8 -year old son and he would laugh at me and say 'mommy I can use this and you can't'. But now I can use the computer. And I must tell you, there are many teachers (at her school) who can't use a computer and even some of them, they even have asked me to teach them in the 
afternoon. So I'm having that status now, that status of someone who is computer literate!

Rules: UCT's recent commitment to a policy for ICT use within the university has certainly influenced my decision to use computers within my lectures. However, another rule driving my use of computers is the current ICT national policy that requires that 'every South African learner in the general and further education and training bands will be ICT capable . . by 2013' (DoE 2003, 21).

Subject position and tools: My decision to use computers as part of my course is motivated by my belief that computers can be used as tools to develop students' conceptual understanding as well as by the current ICT policy at UCT and at a national level. I am also acutely aware of the growing demand in the workplace for technological literacy and feel strongly that teachers (all my students are teachers) need to be able to use new technologies in their own classrooms.

Community: While the community of the lecture hall includes me and my students, the community in the computer laboratory includes a technician and the software designer. Consequently, introducing the computer into my lectures has shifted the community.

Division of labour: Research has shown that the use of computers and cooperative learning methods affects the roles of teacher and students (Mercer and Fisher 1993), with the teacher becoming more of a facilitator and students directing their own pace and sequencing; that is, the introduction of the computer forces a shift from a teacher centred to a student centred approach. While I am still primarily responsible for selecting the content covered in the computer lesson, division of labour has shifted with students taking a more active role in setting the pace of their engagement. My role has also shifted from being almost entirely didactic to being more of a facilitator.

Comparison: Computer laboratory and face-to-face lesson: I began this article with the question: how does a lecturer use a computer to mediate questioning skills and, relatedly does the introduction of the computer force a shift in pedagogical practice? From the data reported above, we can begin to see a shift in the object that the lecturer is working on and, consequently, shifts in various elements of the system. Interestingly, while the face-to-face lesson is primarily concerned with developing students' academic knowledge (or scientific concepts), the laboratory lesson introduces various objects not present in the traditional lecture setting. We have reports from students about the motivating nature of the computer (extract 4) and perhaps most crucially, for a country seeking to overcome the injustices of the past by promoting social justice, the computer is helping some students overcome the digital divide (extract 4 and 5) and positively impacting on their personal development. Much of the computer lesson, however, is devoted to teaching technical skills rather than working on the content I have set. While this might initially seem like a drawback to using computers for teaching, it must be noted that once technical skills are in place, the computer can then be used for higher 
order objects, such as developing academic concepts. One of the most interesting shifts created by the computer is the shifting of my role as teacher to one of facilitator, a role I am unaccustomed to performing. There is definitely a potential contradiction brewing between my beliefs about student learning as a structured, mediated enterprise and the far less structured role I find myself taking in the computer laboratory. As contradictions drive transformation within and between activity systems, we can expect that this developing contradiction will lead to changes both within the activity system of the computer laboratory and the lecture hall. Finally, the most obvious change facilitated by the introduction of the computer is in the community of the computer laboratory. Unlike the lecture room which includes only students and the lecturer in the community, the computer laboratory's community includes a technician as well as the software designer. These new community members are themselves members of wider activity systems and bring their experiences to bear on the activity system in the computer lesson. It is perhaps to be expected that contradictions between the activity system of the computer lesson and the activity system of the software designers will arise. A contradiction currently being worked through relates to my desire for a highly structured learning environment and the software designer's preference for unstructured, exploratory learning. This contradiction is highly productive, giving rise to new online environments, as well as the occasional headache!

\section{CONCLUSION}

This article set out to investigate whether the introduction of a computer-based learning environment would force a shift in a lecturer's pedagogical practice. In order to answer this question, a case study was carried out in 2002 at the University of Cape Town. While I briefly introduced readers to the type of environment used in this case study, time constraints militate against a discussion regarding the effectiveness of this environment on developing students' critical questioning skills (interested readers are referred to Ngambi and Hardman 2004). Although I report findings from only one case, the deeply contextual data collected enables me to make conclusions which I feel will hold across other studies of this kind. Findings indicate that the use of a computer as a teaching/learning tool does indeed force a shift in the activity system, transforming traditional behaviours, leading to contradictions in and between systems and, consequently, forcing changes in and between systems. While this finding is not in itself new and does perhaps seem intuitive (see Mercer and Fisher 1997 for further research about the impact of computing on teaching and learning) the use of activity theory as a framework for tracking changes across an entire system, rather than merely tracking changes within the individual, is still a relatively new way for looking at human computer interaction. 


\section{REFERENCES}

Bodker, S. 1989. A human activity approach to use interfaces. Human Computer Interaction $4(3): 171195$.

. 1991. Through the interface: A human activity approach to user interface design. Hillsdale, NJ: Lawrence Erlbaum.

Cole, M. and Y. Engestrom. 1993. A cultural historical approach to distributed cognition. In Distributed cognition: Psychological and educational considerations, ed. G. Saloman. Cambridge: Cambridge University Press.

Daniels, H. 2001. Vygotsky and pedagogy. New York: Routledge.

Engestrom, Y. 1987. Learning by expanding: An activity theoretical approach to developmental research. Helsinki, Orienta Konsultit Oy.

. 1996. Perspectives on activity theory. Cambridge: Cambridge University Press.

Fontana, L. A., C. Dede, C. S. White and W. M. Cates. 1993. Multimedia; A gateway to higher order thinking skills. Centre for Interactive Educational Technology: George Mason University, VA, ERIC Document Reproduction Service no. ED 362165.

Hardman, J. and D. Ngambi. 2003. A questioning environment for scaffolding learners' questioning engagement with academic text: A university case study. South African Journal of Higher Education 17 (2):139 147.

Jonassen, D. H. and C. S. Carr. 2000. Mindtools: Affording multiple knowledge representations for learning. In Computers as cognitive tools Vol. 2; No more walls, ed. S. P. Lajoie. Mahwah, NJ: Lawrence Erlbaum.

Kaptelinin, V. 1996. Computer mediated activity: Functional organs in social and developmental contexts. In Context and consciousness: Activity theory and human computer interaction, ed. B. Nardi. Cambridge, MA: MIT Press.

Kearnery, M. and D. F. Treagust. 2001. Constructivism as an efferent in the design and development of a computer program using interactive digital video to enhance learning in physics. Australian Journal of Educational Technology 17 (1):64 79.

Kuutti, K. 1996. Activity theory as a potential framework for human computer interaction research. In Context and consciousness: Activity theory and human computer interaction, ed. B. Nardi. Cambridge, MA: MIT Press.

Lim, C. P. and C. S. Chai. 2004. An activity theoretical approach to research of ICT integration in Singapore schools: Orienting activities and learner autonomy. Computers and education 43 (1):215 236.

Mercer, N. and E. Fisher. 1997. Scaffolding through talk. In Computers and talk in the primary classroom, ed. R. Wegerif and P. Scrimshaw. Clevedon, Multilingual Matters.

Nardi, B. ed. 1996. Context and consciousness: Activity theory and human computer interaction. Cambridge, MA: MIT Press.

. 1998. Concepts of cognition and consciousness: Four voices. Journal of Computer Documentation $22(1): 3148$.

Ngambi, D. and J. Hardman. 2004. Towards a knowledge sharing scaffolding environment based on student questions. British Journal of Educational Technology 35 (2):187 197.

Russell, D. 2002. Looking beyond the interface: Activity theory and distributed learning. In Distributed learning, ed. M. Lea and K. Nicoll. London: Routledge Falmer.

South African Government September. 2003. White paper: Draft E Education White Paper: Call For Written Submissions from Stakeholder Bodies and Members of the Public. http:// education.pwv.gov.za/index.asp?src=docu\&xsrc=legi\&ysrc $=$ White $\% 20$ Papers.

Valsiner, J. 1998. The guided mind: A sociogenetic approach to personality. Cambridge MA: Harvard University Press. 
Vygotsky, L. S. 1962. Thought and language. Ed. and trans. E. Hanfmann and G. Vakar. Cambridge, MA: MIT Press.

. 1978. Mind in society: The development of higher psychological processes. Ed. and trans. M. Cole, V. John Steiner, S. Scribner and E. Souberman. Cambridge, MA: Harvard University Press.

Zinchenko, V. 1996. Developing activity theory: The zone of proximal development and beyond. In Context and consciousness: Activity theory and human computer interaction, ed. M. Lea and K. Nicoll. Cambridge, MA: MIT Press. 